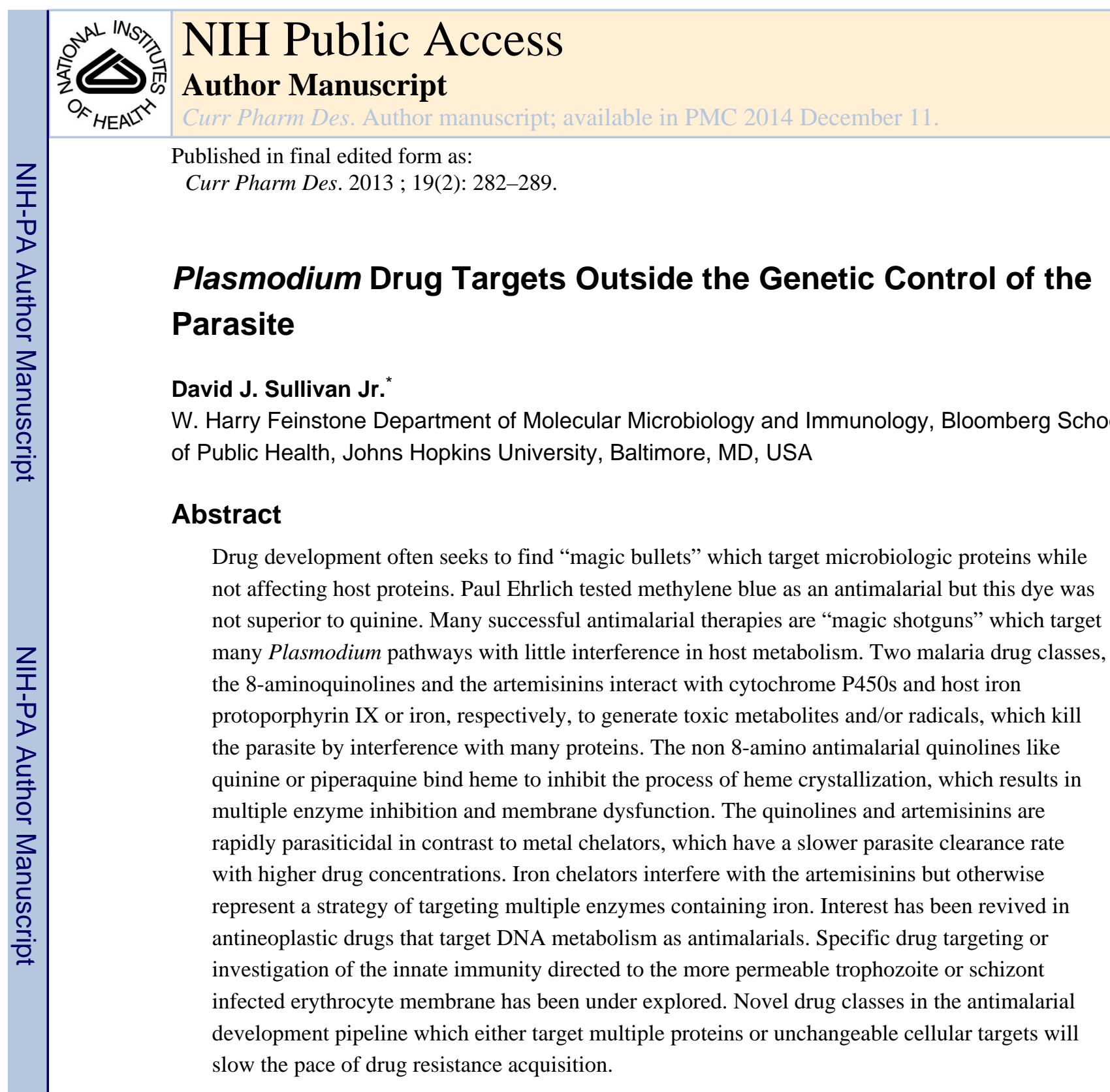

Keywords

Heme; drug; iron; malaria; host defense peptide

\title{
IMMUTABLE TARGETS
}

One strategy to combat drug resistance is to discover Plasmodium drug targets outside genetic control of parasites. In a pure sense for an established parasite this is difficult to

(C) 2013 Bentham Science Publishers

*Address correspondence to this author at the W. Harry Feinstone Department of Molecular Microbiology and Immunology, Bloomberg School of Public Health, Johns Hopkins University, 615 North Wolfe Street, E5628, Baltimore, MD 21205 USA; Tel: +1 410 502-2522; Fax: +1 410 955-0105; dsulliva@jhsph.edu.

Send Orders of Reprints at reprints@benthamscience.org

CONFLICT OF INTEREST

The author confirms that this article content has no conflicts of interest. 
achieve on the basis that microorganisms are capable of altering drug transporters as well as the drug target. For this discussion Plasmodium heme and metal metabolism as well as DNA or membranes will be considered targets outside the control of the parasite. Drugs like atovaquone or pyrimethamine which target single proteins or enzymes, "magic bullets", have a minor (in numbers only) but important role amongst the clinically active antimalarials. Most antimalarial regimens include multiple drugs to target multiple pathways both to deter drug resistance and increase the parasite clearance rate. Many antimalarials as single drugs target multiple pathways behaving like "magic shotguns" rather than "magic bullets". Recently the malERA Consultative Group on Drugs has defined the ideal malaria eradication drug to be one that "is a coformulated drug combination suitable for mass administration that can be administered in a single encounter at infrequent intervals and that results in radical cure of all life cycle stages of all five malaria species infecting humans" [1]. Implicit to this strategy is lack of drug resistance. This review highlights nonprotein, nonenzyme Plasmodium targets like heme, metals, DNA or membranes many of which are the basis for validated malaria drugs or potential drugs acting on multiple stages.

\section{MAGIC BULLETS}

Paul Ehrlich first sought to discover the ideal drug, therapia sterlisans magna. The translation is a single dose treatment, which destroys all microorganisms in the infected organism, a definition very similar to the modern malERA definition. In his own words he sought optimal agents, which combine high parasitotropism with low organotropism. Drugs would act like "magic bullets" without affecting the host cell [2]. He started by working on methylene blue, which, while curative, was not superior to quinine. He noted that this drug also had high affinity for the parasite and low toxicity for the patients [3]. More recent work suggests that methylene blue may both target thiol (glutathione) metabolism as well as heme crystallization in Plasmodium parasites with activity against both erythrocyte and gametocyte stages [4-8]. A recent clinical trial indicates some promise for methylene blue [9]. In the first ever synthetic drug screen to find an selective agent for syphilis, Paul Ehrlich started from aminophenyl arsenic acid which went by the name of Atoxyl and was in use for African sleeping sickness [3]. After exploring inhibition of microbes and host toxicity of 605 compounds he modified arsenophenol to produce arsphenamine, better known as compound 606. A Japanese student tested all the arsenicals in Ehrlich's collection including compound 606 against the spirochetes of syphilis. He noted the curative properties in rabbits. Soon the arsphenamine was tried in a few syphilis patients and then Ehrlich provided 65,000 free samples so that more clinical studies could be performed. Finally Hoechst marketed the drug the name Salvarsan, meaning "arsenic that saves". This was the first effective drug against syphilis. Treatment was prolonged for 18 months requiring painful injections and was not single dose [3]. Not until the long lasting penicillins did clinicians have access to single dose therapy for syphilis.

The clinical antibacterial antimalarials target apicoplast or possibly mitochondrial prokaryote targets including the DNA gyrases, RNA polymerases and small ribosomal subunits to inhibit parasites in a post generational effect [10,11]. The antifolates disrupt nucleotide pools by inhibition of two successive enzymes in the folate synthesis pathway, dihydrofolate reductase and dihydropteroate synthetase [12-14]. Atavoquone collapses 
mitochondrial membrane potential by interaction with the cytochrome $b$ gene product [15]. The macrolides, antifolates and atovaquone can be considered traditional "magic bullets" with a specific drug interacting with a specific pocket in an enzyme to kill the Plasmodium parasite.

\section{MAGIC SHOTGUNS}

For neurologic diseases the term magic shotgun has recently been applied to neuroactive drugs which are able to influence multiple processes at once in the brain as an organ [16, 17]. Primaquine, artemisinins and the quinolines are also more like "magic shotguns" as antimalarials on a single cell level. Primaquine is activated in mitochondria to generate toxic radicals or toxins which kill certain stages but not $P$. falciparum blood stages [18]. The artemisinins are activated by iron or heme to generate carbon-centered radicals which damage nearby proteins [19-23]. The quinolines target the process of heme crystallization [24-26]. Both primaquine and the artemisinins are metabolized to generate damage to innocent bystander proteins. The antimalarial quinolones used clinically to target erythrocytes stages interfere with heme metabolism to create a cascade of downstream cellular disruptions including enzyme and membrane damage.

For malaria, specific effective curative drug therapy in the form of an extract from the bark of the cinchona tree preceded discovery of the microorganism by more than 250 years [27]. Pure quinine or quinidine and the cinchona alkaloids were able to be easily purified and used by the late 1800's [28]. Quinine therapy for cyclical malaria fevers is unpleasant with the symptom complex of tinnitus, nausea and dizziness called "cinchonism" present at therapeutic drug levels [29]. Therapy must be continued for at least seven days. Quinine also can affect conduction in the heart and rarely causes blindness or purpura [30-32]. Quinine, borrowing the words of Ehrlich, has high parasitotropism but moderate organotropism and has to be delivered over 7 days. The mechanism of action, although still debatable, has centered upon interference with heme crystallization in the parasite's erythrocyte stage [25, 33]. Despite hundreds of years of use, quinine resistance has been sporadic and not sustained unlike chloroquine in which after a few decades in some regions of the world like Southeast Asia chloroquine resistance is now almost fixed [34-36].

\section{DRUG RESISTANCE}

Microorganisms have three options to become resistant to drugs. They can metabolize or detoxify the drug, have less drug pumped in to the target or pump out more drug, or alter the drug target either by changing amino acids or making more of the enzyme to compensate [37]. Classic examples of metabolizing drugs are the beta lactamases which degrade penicillin. Bacteria can also alter the amino acid sequence of penicillin binding proteins or ribosomal targets in the case of the macrolide antibiotics. Many bacterial transporters pump out the tetracyclines. In cancer the P-glycoproteins can function as multidrug transporters even though the physiologic substrate of this protein substrate has not been determined [38]. Many cell types can increase target enzyme transcription, as in the case of methylene blue, and compensate, e.g. by increasing the glutathione synthesis pathway [6, 7]. Antibiotic resistance is ancient. Bacteria have evolved for eons competing for limited resources and 
making antibiotics to limit foreign bacteria. An ancient cave microbiome isolated for over 4 million years contained drug resistance genotypes to 14 present commercially available antibiotics $[39,40]$. Microbial drug resistance is never a question of "if" but a matter of "when".

In the case of Plasmodium, the parasite by biochemical testing does not have capability to alter drugs. While the parasite has a cytochrome $\mathrm{P} 450$ reductase homolog there is not a cytochrome P450 homolog or monooxygenases [41]. Experiments which combined many of the malaria drugs with parasite lysates yielded no drug changes [42, 43]. The case of the artemisinins are different in that they are first activated by iron or heme, produce a carbon centered radical and then are inactive [44]. Well known examples of target site alteration have been documented for atovaquone and the cytochrome $b$ changes, and for the antifolates and alteration of dihydrofolate reductase and dihydropteroate synthetase [45]. Chloroquine and many related quinoline concentrations in the digestive vacuole are lower by an alteration in the P. falciparum chloroquine resistant transporter [46, 47]. Malariologists agree that chloroquine resistant parasites have lower chloroquine concentrations in digestive vacuoles but whether by a PfCRT pump or channel mechanism or by modulation of $P$. falciparum multidrug transporter 1 or other transporters is still debated [47]. Single nucleotide polymorphisms and copy number variation of the $P$. falciparum multidrug transporter 1 are associated with chloroquine resistance but copy number variation is the determinant for mefloquine resistance which decreases accumulation of the drug [48, 49]. In some murine malaria models artemisinin or chloroquine resistant mice invade preferentially reticulocytes which are transcriptionally responsive [50-52].

The intrinsic rate at which P. falciparum parasites acquire single nucleotide polymorphisms in on the order of $10^{-9}$ [53]. This explains why patients with $10^{11}$ or more parasites are able to acquire atovaquone-resistant parasites on single drug therapy [54]. Pradip Rathod elegantly conceptualized that different $P$. falciparum isolates have slightly different intrinsic mutation rates which alters their ability to acquire resistance to different drugs [55]. Indeed alterations in the dihydrofolate reductase gene may also increase the rate of acquiring mutations on other genes. Use of two separate drugs which target two separate enzymes would then require on the order of $10^{-18}$ parasites which is close to the total world population of $P$. falciparum parasites [56]. Likewise a single drug targeting two proteins or enzymes like a "magic shotgun" would also decrease drug resistance development in the absence of drug pumps [57].

\section{HOST CELL CHARACTERIZATION}

The hepatocyte is approximately $20-30$ micrometers in diameter. This polarized epithelial cell has three distinct surfaces: 1. Basolateral or sinusoidal (37\% of surface) which contacts the plasma via the endothelial cells with a large sinus. The space of Disse is at this interface; 2. Apical or canalicular surface (13\%) that compromises the bile canaliculus and 3. the lateral or contiguous surface (50\%). The sinusoidal and canalicular surfaces are maximized by microvilli. Mitochondria occupy about $20 \%$ of a hepatocyte cell volume. The hepatocytes in additional to usual cell organelles have peroxisomes for oxidative reactions. The liver expresses more than $90 \%$ of plasma proteins or about $15 \%$ of protein content of the human 
body. In addition to the normal housekeeping genes liver specific genes code for plasma proteins, glucose production, glycogen, cholesterol regulation, bile production and detoxification of normal waste and exogenous compounds. Liver cells do not divide frequently with less than $1 / 10,000$ in mitosis at any one time. The epidermis of the skin has a mitotic rate of $1 / 1000$ [58].

The host erythrocyte is composed principally of water, then hemoglobin and nonhemoglobin enzymes both to transport $\mathrm{CO}_{2}$ and keep heme iron reduced in order to transport oxygen. Heme is present at $20 \mathrm{mM}$, with bioavailable iron at about $5 \mu \mathrm{M}$ either in erythrocyte ferritin or a calcein chelatable pool bound to low molecular weight solutes [59, 60]. Two other transition metals zinc and copper are present in carbonic anhydrase and the copper-zinc superoxide dismutase [61]. Intraerythrocyte concentrations of zinc are about $150 \mu \mathrm{M}$ while copper is about $20 \mu \mathrm{M}$ [62]. When the Plasmodium parasite ingests host cytosol to degrade hemoglobin the enzymes containing these transition metals are also degraded. The Plasmodium parasites lack molecules like ferritin or metallothionen to buffer these reactive transitional metals [60].

\section{PRIMAQUINE-AN 8-AMINOQUINOLINE}

Primaquine kills late stage gametocytes and liver stages as charted in Table 1. The target in the parasite is probably the mitochondria with morphologic changes first occurring there [18]. Primaquine in the human liver is metabolized to produce toxic metabolites as a byproduct. In vitro primaquine is inactive against gametocytes and also erythrocytic stages. There is no in vivo blood stage activity indicating that the reactive metabolite is unable to reach the mitochondria in blood stages or that like in the liver gametocytes may be able to generate toxic metabolites from primaquine although evidence of primaquine uptake in gametocytes is sparse. Structure activity relationships indicate that toxicity is difficult to separate from Plasmodium activity. However in a review of the older literature administration of quinine with primaquine increased activity and did not change the toxicity of primaquine [63]. The hypothesis is that these quinolines compete for cytochrome P450 interaction. Multiple cytochrome P450 enzymes have been shown to produce erythrocyte toxicity (and therefore malaria specific activity by association) measured by methemoglobin production, reactive oxygen intermediates or thiol depletion. Primaquine toxicity was reversed by cytochrome P450 2B6, 2D6 and 3A4 inhibition [64]. The active metabolites were shown not to cause accelerated eryptosis (a modified, truncated process of apoptosis specific to the erythrocyte) indicated by flipping of phosphytidyl serine and calcium fluxes [65]. These active metabolites most likely damage multiple protein targets in the mitochondria rather than just one target which places the 8-aminoquinolines in the "magic shotgun" category.

\section{ARTEMISININS}

The important structural feature of the artemisinins is the endoperoxide bridge. Another single drug called ascaridole which can be used as a luminal drug for helminths contains the endoperoxide bridge $[66,67]$. The essential chemistry of the artemisinins is activation by iron or heme to generate a carbon centered radical which damages innocent bystander 
proteins like a "magic shotgun" in either the digestive vacuole or parasite cytosol [44, 68, 69]. Among proteins and transporters specifically damaged is the calcium AT-Pase 6 [23]. Iron chelators are antagonistic to activation and activity of the artemisinins and should not be used concurrently [59]. The artemisinins are not active against liver stages and early ring stages but have a broad window of blood stage toxicity from early ring to schizont stages including early and mature gametocytes as seen in Table 1 [70]. The artemisinins make heme adducts and heme adduct formation correlates with activity [20, 21]. However if the iron chelators, which are unable to chelate heme iron, can antagonize artemisinin action this suggests liberation of iron in a parasite compartment is critical to action. Heme could still be degraded by glutathione or other peroxidases to yield the critical iron for artemisinin action. A single artemisinin molecule is activated and produces radicals and then is no longer functional. In this regards it has been called a suicide molecule. Hemichromes present in thalassemic erythrocytes are able to bind artemisinin drug in uninfected erythrocytes increasing the $\mathrm{IC}_{50}$ to about $20-30 \mathrm{nM}$ from baseline levels of less than $10 \mathrm{nM}$ [71, 72]. Artemisinin is able to bind heme but not inhibit heme crystallization [73], despite a few papers stating inhibition of heme crystallization by the artemisinins [74, 75]. Binding of heme in hemichromes may contribute to delayed parasite clearance $[76,77]$ in individuals with hemoglobin E, which can be present in $30 \%$ of the population in Southeast Asia.

\section{HEME CRYSTAL INHIBITION}

The quinolines target the process of heme crystallization [78]. Hemozoin is a very unique abundant pathway in the Plasmodium parasite which represents a "magic bullet" target seen in Fig. (1). The non 8-aminoquinolines are active against blood stages which contain submicroscopic hemozoin and early stage gametocytes. They are not active against earlier ring stages in which artemisinins are active and later gametocyte stages Table 1.

Chloroquine is active against $P$. vivax gametocytes in contrast to $P$. falciparum gametocytes [79]. However in the final analysis the quinolines like quinine are "magic shotguns" with additional targets that are either direct downstream effects of heme crystal inhibition or off target effects like potassium channel inhibition. Indeed the quinoline substructure is rather promiscuous amongst approved FDA drugs appearing in 14 other drug indication categories from antineoplastics, topical antibacterials and even a bronchodilator Fig. (2). Mefloquine is being explored as a mycobacterial drug [80] and also as an antiviral in Jacob Cruezfeldt disease, also known as progressive multifocal leukoencephalopathy [81-83].

Quinine also was used for many other medical conditions including alcoholism, alopecia, anemia, colds, shingles, influenza, and bacterial infections including pneumonia and varicose veins. In addition, quinine was found in many commercial cold and fever remedies, as well as in some sunburn medicines, hair tonics and bitter tonics [84]. Quinine has also been used for leg cramps [85]. Quinine was used in large part because it affects sodium potassium pumps, which relax muscle tissue. To that end, a meta-analysis published in 1995 looking at six randomized double blind studies indicated that quinine reduced the number of cramps over a 4 week period by 8.8 cramps, but that the duration and intensity of the cramps was not reduced [86]. The FDA has issued directives to limit use of quinine for leg cramps because of purpuric rare idiosyncratic side effects $[87,88]$. 
The survey of antimalarial drugs which identified chloroquine screened 12,318 compounds of which 1,935 contained the quinoline substructure-659 4-aminoquinolines and 488 8aminoquinolines. This substructure has had much published on structure activity relationships [89-91]. Basically the quinoline nucleus is essential for heme binding, the chlorine and hydroxyl entities for heme crystal inhibition and the amino weak bases for digestive vacuole accumulation. Not all drugs that bind heme inhibit heme crystal formation. Not all drugs that bind heme and inhibit heme crystal formation accumulate at the target site and kill the parasite $[24,25,92,93]$. Chloroquine and quinine differ in their off rates in equilibrium binding to hemozoin with quinine and quinidine having a slower off rate [33, 94].

\section{METAL CHELATORS}

While heme has been a clinically relevant malaria drug target, to date the other nonmutable free metal drug targets have not been successful. The three metals iron, copper and zinc are essential to many cellular processes as seen in Table 2. Iron and copper are reduction and oxidation (redox) active and are carefully chaperoned. Interestingly reduced iron and oxidized copper are water soluble while the opposite - oxidized iron and reduced copper are insoluble. Zinc has a full electron orbital and stable valence, so is not redox active. However zinc can be a strong Lewis acid with its small radius and high electron charge. All three metals can be toxic if homeostasis is perturbed.

Sequestration of iron is a common host defense strategy to fight infectious agents [95]. Dietary iron deficiency protects mice against $P$. chabaudi, decreasing mortality and parasitemia [96]. Iron depletion for short periods with an iron chelator could increase the host response against Plasmodium without major host damage. Studies have shown that iron chelators inhibit Plasmodium growth in culture, with a greater effect on the trophozoite stage [97, 98]. In addition, iron chelators inhibit liver stage malaria and iron supplementation increases merozoite numbers exiting from the liver [99]. Therefore, iron chelation and iron deficiency can inhibit Plasmodium growth in vivo. Iron chelators are active against both liver and erythrocytes stages in vitro and in animal malaria models probably by inhibition the DNA synthesis function of ribonucleotide reductase [100] as seen in Table 1. Plasmodium does not have siderophores or hemophores for iron import, nor does it have receptors for human plasma iron carriers (transferrin, ferritin or lactoferrin).

Plasmodium also does not have a functional heme oxygenase to release heme iron from hemoglobin digestion, but sequesters heme as heme crystal in a lysosome like vacuole precluding re-use of iron [60]. Experimental evidence indicates a low molecular weight chelatable non-ferritin pool in erythrocytes, which provides bioavailable iron [99]. How the intrahepatocyte Plasmodium obtains iron has not been delineated. During gametocytogenesis, the tricarboxylic acid cycle is more active $[101,102]$ to produce succinyl Co-A for heme biosynthesis [103]. In P. falciparum, cytochrome b, which binds two heme groups, has an increased expression of several fold in sexual stages [104]. Also, mRNAs of three of the six genes involved in heme biosynthesis are up-regulated during gametocytogenesis [105]. The metabolism of gametocytes and their iron requirements have not been explored in detail but potentially can be targeted. The intravenous iron chelator desferoxamine failed to increase survival in a severe malaria study and is also difficult to 
administer [106]. Deferoxamine (DFO) and Deferiprone, two iron chelators to treat transfusional iron overload, have also shown antimalarial activity. However, they do not have safety or pharmacokinetic properties acceptable to be used as antimalarial drugs. DFO has a twenty-minute half-life needing continuous parental infusion because the drug is not orally available [107]. Deferiprone has a half-life of 1-2 hours needing multiple daily doses and although the drug is orally available is also associated with fatal agranulocyotisis [107].

In addition to a static cell cycle action via cessation of DNA synthesis, some noniron metal chelators perturb metal pools with changes in compartment. The chemical state of chelation also may render the metal more redox active generating more reactive radicals inside the cell resulting in nonspecific protein damage. The 8-hydroxyquinoline also doubles as a chelator of copper and zinc shuttling both to new compartments to cause damage [108]. This is yet another role for quinolines.

\section{DNA TARGETS}

The malaria parasite resides in succession in the human host in two very different host cellsthe hepatocyte and the erythrocyte. The hepatocyte is one of the more metabolically active cells in its function to rid the body of its metabolic waste, detoxify exogenous poisons and drugs and produce anti-inflammatory molecules and endocrine proteins. The parasite exists within a parasitophorous vacuole living off the largesse of the heptocyte host. During its lifespan in the liver the Plasmodium parasite multiplies from a single cell to more than 10,000 in less than a week. 32,768 is $2^{15}$, which represents a nuclear division about every 12 hours in the case of all the human malaria species [79]. The mouse species produce about 5 to 10 thousand in 45 hours or about 4,096 or $2^{12}$, which represents a nuclear division every 4 hours [109]. In the human erythrocyte the outcome of nuclear division decreases to 16 to 32 progeny in 48 hours or 4 divisions in 48 hours with an average of 1 every 12 hours. This rapid pace of DNA multiplication makes DNA interference an attractive target for both liver stage and blood stage activity.

Antineoplastic chemotherapy which targets DNA replication Table 1 has recently been revived with a human malaria clinical trial for methotrexate [110]. Other cancer agents are effective against the malaria parasites with probable off target action [111]. In general we still have safer antimalarial drugs before availing of more toxic cancer drugs.

\section{INNATE HOST DEFENSE TARGETS MEMBRANES}

The innate immune system produces an array of small peptides like defensins which in general target membranes [112]. Translating these small peptides into drugs meets obstacles of target site delivery through the gastrointestinal tract and delivery to the target site [113]. The only Plasmodium stages exposed to the innate immune system are the sporozoite stage and merozoites. The five human Plasmodium are a subset of the more than 100 Plasmodium which infect birds, reptiles, turtles, and many mammals. Interestingly the domestic animals of humans like the dog, cat, horse and pig all lack Plasmodium species capable of infection. This raises the question of innate system defense in these potential mammalian hosts. The trophozoite and schizont stages both have a greater permeability to low molecular weight 
solutes and are subject to osmotic lysis and this possibly makes the infected erythrocytes more susceptible to membrane targeting [112].

\section{CONCLUSION}

The Medicines for Malaria Venture (MMV) has a robust pipeline [114]. Ideally drugs which can either target multiple enzymes or target the metals are still robust chemical space for antimalarials. The malaria parasite does contain unique nonprotein drug targets revolving around metals in the transitional iron and heme, which are related to multiple metabolic pathways.

\section{Acknowledgments}

The author acknowledges partial support by the Bloomberg Foundation via the Johns Hopkins Malaria Research Institute and partial support by the National Institutes of Health 5U01 HD061241-03.

\section{References}

1. Drugs TmcGo. A research agenda for malaria eradication: drugs. PLoS Med. 2011; 8(1):e1000402. [PubMed: 21311580]

2. Gensini GF, Conti AA, Lippi D. The contributions of Paul Ehrlich to infectious disease. J Infect. 2007; 54(3):221-4. [PubMed: 16567000]

3. Bosch F, Rosich L. The contributions of Paul Ehrlich to pharmacology: a tribute on the occasion of the centenary of his Nobel Prize. Pharmacology. 2008; 82(3):171-9. [PubMed: 18679046]

4. Adjalley SH, Johnston GL, Li T, et al. Quantitative assessment of Plasmodium falciparum sexual development reveals potent transmission-blocking activity by methylene blue. Proc Natl Acad Sci U S A. 2011; 108(47):E1214-23. [PubMed: 22042867]

5. Coulibaly B, Zoungrana A, Mockenhaupt FP, et al. Strong gametocytocidal effect of methylene blue-based combination therapy against falciparum malaria: a randomised controlled trial. PLoS One. 2009; 4(5):e5318. [PubMed: 19415120]

6. Blank O, Davioud-Charvet E, Elhabiri M. Interactions of the antimalarial drug methylene blue with methemoglobin and heme targets in Plasmodium falciparum: A physico-biochemical study. Antioxid Redox Signal. 2012

7. Schirmer RH, Coulibaly B, Stich A, et al. Methylene blue as an antimalarial agent. Redox Rep. 2003; 8(5):272-5. [PubMed: 14962363]

8. Atamna H, Krugliak M, Shalmiev G, et al. Mode of antimalarial effect of methylene blue and some of its analogues on Plasmodium falciparum in culture and their inhibition of $P$. vinckei petteri and P. yoelii nigeriensis in vivo. Biochem Pharmacol. 1996; 51(5):693-700. [PubMed: 8615907]

9. Bountogo M, Zoungrana A, Coulibaly B, et al. Efficacy of methylene blue monotherapy in semiimmune adults with uncomplicated falciparum malaria: a controlled trial in Burkina Faso. Tropical medicine \& international health : TM \& IH. 2010; 15(6):713-7. [PubMed: 20374561]

10. Lee Y, Choi JY, Fu H, et al. Chemistry and biology of macrolide antiparasitic agents. J Med Chem. 2011; 54(8):2792-804. [PubMed: 21428405]

11. Botte CY, Dubar F, McFadden GI, Marechal E, Biot C. Plasmodium falciparum apicoplast drugs: targets or off-targets? Chem Rev. 2012; 112(3):1269-83. [PubMed: 22026508]

12. Jelinek T, Ronn AM, Lemnge MM, et al. Polymorphisms in the dihydrofolate reductase (DHFR) and dihydropteroate synthetase (DHPS) genes of Plasmodium falciparum and in vivo resistance to sulphadoxine/pyrimethamine in isolates from Tanzania. Trop Med Int Health. 1998; 3(8):605-9. [PubMed: 9735930]

13. Curtis J, Duraisingh MT, Warhurst DC. In vivo selection for a specific genotype of dihydropteroate synthetase of Plasmodium falciparum by pyrimethamine-sulfadoxine but not chlorproguanildapsone treatment. J Infect Dis. 1998; 177(5):1429-33. [PubMed: 9593041] 
14. Wang P, Brobey RK, Horii T, Sims PF, Hyde JE. Utilization of exogenous folate in the human malaria parasite Plasmodium falciparum and its critical role in antifolate drug synergy. Mol Microbiol. 1999; 32(6):1254-62. [PubMed: 10383765]

15. Mather MW, Darrouzet E, Valkova-Valchanova M, et al. Uncovering the molecular mode of action of the antimalarial drug atovaquone using a bacterial system. J Biol Chem. 2005; 280(29): 27458-65. [PubMed: 15917236]

16. Musk P. Magic shotgun methods for developing drugs for CNS disorders. Discov Med. 2004; 4(23):299-302. [PubMed: 20704963]

17. Roth BL, Sheffler DJ, Kroeze WK. Magic shotguns versus magic bullets: selectively non-selective drugs for mood disorders and schizophrenia. Nat Rev Drug Discov. 2004; 3(4):353-9. [PubMed: 15060530]

18. Vale N, Moreira R, Gomes P. Primaquine revisited six decades after its discovery. Eur J Med Chem. 2009; 44(3):937-53. [PubMed: 18930565]

19. Bhisutthibhan J, Pan XQ, Hossler PA, et al. The Plasmodium falciparum translationally controlled tumor protein homolog and its reaction with the antimalarial drug artemisinin. J Biol Chem. 1998; 273(26):16192-8. [PubMed: 9632675]

20. Hong YL, Yang YZ, Meshnick SR. The interaction of artemisinin with malarial hemozoin. Mol Biochem Parasitol. 1994; 63(1):121-8. [PubMed: 8183310]

21. Meshnick SR. Artemisinin: mechanisms of action, resistance and toxicity. Int J Parasitol. 2002; 32(13):1655-60. [PubMed: 12435450]

22. Meshnick SR, Taylor TE, Kamchonwongpaisan S. Artemisinin and the antimalarial endoperoxides: from herbal remedy to targeted chemotherapy. Microbiol Rev. 1996; 60(2):30115. [PubMed: 8801435]

23. Eckstein-Ludwig U, Webb RJ, Van Goethem ID, et al. Artemisinins target the SERCA of Plasmodium falciparum. Nature. 2003; 424(6951):957-61. [PubMed: 12931192]

24. Pisciotta JM, Sullivan D. Hemozoin: oil versus water. Parasitol Int. 2008; 57(2):89-96. [PubMed: 18373972]

25. Sullivan DJ Jr, Gluzman IY, Russell DG, Goldberg DE. On the molecular mechanism of chloroquine's antimalarial action. Proc Natl Acad Sci U S A. 1996; 93(21):11865-70. [PubMed: 8876229]

26. Weissbuch I, Leiserowitz L. Interplay between malaria, crystalline hemozoin formation, and antimalarial drug action and design. Chem Rev. 2008; 108(11):4899-914. [PubMed: 19006402]

27. Bruce-Chwatt LJ. Three hundred and fifty years of the Peruvian fever bark. Br Med J (Clin Res Ed). 1988; 296(6635):1486-7.

28. Delepine M. Joseph Pelletier and Joseph Caventou. J Chem Educ. 1951; 28(9):454-61.

29. Taylor WR, White NJ. Antimalarial drug toxicity: a review. Drug Saf. 2004; 27(1):25-61. [PubMed: 14720085]

30. Touze JE, Heno P, Fourcade L, et al. The effects of antimalarial drugs on ventricular repolarization. Am J Trop Med Hyg. 2002; 67(1):54-60. [PubMed: 12363064]

31. Bacon P, Spalton DJ, Smith SE. Blindness from quinine toxicity. Br J Ophthalmol. 1988; 72(3): 219-24. [PubMed: 3281709]

32. Vipan WH. Quinine as a cause of purpura. Lancet. 1865; 86(2184):37.

33. Sullivan DJ Jr, Matile H, Ridley RG, Goldberg DE. A common mechanism for blockade of heme polymerization by antimalarial quinolines. J Biol Chem. 1998; 273(47):31103-7. [PubMed: 9813011]

34. Peters W. Plasmodium: resistance to antimalarial drugs. Ann Parasitol Hum Comp. 1990; 65(Suppl):1103-6.

35. van den Broek IV, van der Wardt S, Talukder L, et al. Drug resistance in Plasmodium falciparum from the Chittagong Hill Tracts, Bangladesh. Trop Med Int Health. 2004; 9(6):680-7. [PubMed: 15189458]

36. Na-Bangchang K, Congpuong K. Current malaria status and distribution of drug resistance in East and Southeast Asia with special focus to Thailand. Tohoku J Exp Med. 2007; 211(2):99-113. [PubMed: 17287593] 
37. Wise R. A review of the mechanisms of action and resistance of antimicrobial agents. Can Respir J. 1999; 6(Suppl):A20A-2A.

38. Savas B, Cole SP, Akoglu TF, Pross HF. P-glycoprotein-mediated multidrug resistance and cytotoxic effector cells. Nat Immun. 1992; 11(4):177-92. [PubMed: 1358293]

39. Bhullar K, Waglechner N, Pawlowski A, et al. Antibiotic resistance is prevalent in an isolated cave microbiome. PLoS One. 2012; 7(4):e34953. [PubMed: 22509370]

40. Drewniak L, Styczek A, Majder-Lopatka M, Sklodowska A. Bacteria, hypertolerant to arsenic in the rocks of an ancient gold mine, and their potential role in dissemination of arsenic pollution. Environ Pollut. 2008; 156(3):1069-74. [PubMed: 18550235]

41. Aurrecoechea C, Brestelli J, Brunk BP, et al. PlasmoDB: a functional genomic database for malaria parasites. Nucleic Acids Res. 2009; 37(Database issue):D539-43. [PubMed: 18957442]

42. Berger BJ, Martiney J, Slater AF, Fairlamb AH, Cerami A. Chloroquine resistance is not associated with drug metabolism in Plasmodium falciparum. J Parasitol. 1995; 81(6):1004-8. [PubMed: 8544038]

43. Robert A, Dechy-Cabaret O, Cazelles J, Meunier B. From mechanistic studies on artemisinin derivatives to new modular antimalarial drugs. Acc Chem Res. 2002; 35(3):167-74. [PubMed: 11900520]

44. Posner GH, O’Neill PM. Knowledge of the proposed chemical mechanism of action and cytochrome p450 metabolism of antimalarial trioxanes like artemisinin allows rational design of new antimalarial peroxides. Acc Chem Res. 2004; 37(6):397-404. [PubMed: 15196049]

45. Muller IB, Hyde JE. Antimalarial drugs: modes of action and mechanisms of parasite resistance. Future Microbiol. 2010; 5(12):1857-73. [PubMed: 21155666]

46. Wellems TE, Plowe CV. Chloroquine-resistant malaria. J Infect Dis. 2001; 184(6):770-6. [PubMed: 11517439]

47. Roepe PD. PfCRT-Mediated Drug Transport in Malarial Parasites. Biochemistry. 2010

48. Valderramos SG, Fidock DA. Transporters involved in resistance to antimalarial drugs. Trends Pharmacol Sci. 2006; 27(11):594-601. [PubMed: 16996622]

49. Woodrow CJ, Krishna S. Antimalarial drugs: recent advances in molecular determinants of resistance and their clinical significance. Cell Mol Life Sci. 2006; 63(14):1586-96. [PubMed: 16699808]

50. Chandra R, Kumar S, Puri SK. Plasmodium vinckei: infectivity of arteether-sensitive and arteetherresistant parasites in different strains of mice. Parasitol Res. 2011; 109(4):1143-9. [PubMed: 21479576]

51. Wood PA, Eaton JW. Hemoglobin catabolism and host-parasite heme balance in chloroquinesensitive and chloroquine-resistant Plasmodium berghei infections. Am J Trop Med Hyg. 1993; 48(4):465-72. [PubMed: 8480854]

52. Biarnais T, Landau I, Richard-Lenoble D. Changes in schizogony and drug response in two lines of rodent Plasmodium, P. berghei NK 65 and P. berghei. ANKA. Parasite. 2002; 9(1):51-7. [PubMed: 11938696]

53. Paget-McNicol S, Saul A. Mutation rates in the dihydrofolate reductase gene of Plasmodium falciparum. Parasitology. 2001; 122(Pt 5):497-505. [PubMed: 11393822]

54. Berry A, Senescau A, Lelievre J, et al. Prevalence of Plasmodium falciparum cytochrome b gene mutations in isolates imported from Africa, and implications for atovaquone resistance. Trans $\mathrm{R}$ Soc Trop Med Hyg. 2006; 100(10):986-8. [PubMed: 16690094]

55. Rathod PK, McErlean T, Lee PC. Variations in frequencies of drug resistance in Plasmodium falciparum. Proc Natl Acad Sci U S A. 1997; 94(17):9389-93. [PubMed: 9256492]

56. White NJ. Antimalarial drug resistance. J Clin Invest. 2004; 113(8):1084-92. [PubMed: 15085184]

57. White NJ. Delaying antimalarial drug resistance with combination chemotherapy. Parassitologia. 1999; 41(1-3):301-8. [PubMed: 10697872]

58. Fisher LB. Determination of the normal rate and duration of mitosis in human epidermis. Br J Dermatol. 1968; 80(1):24-8. [PubMed: 5635592] 
59. Ferrer P, Tripathi AK, Clark MA, et al. Antimalarial Iron Chelator, FBS0701, Shows Asexual and Gametocyte Plasmodium falciparum Activity and Single Oral Dose Cure in a Murine Malaria Model. PLoS One. 2012; 7(5):e37171. [PubMed: 22629364]

60. Scholl PF, Tripathi AK, Sullivan DJ. Bioavailable iron and heme metabolism in Plasmodium falciparum. Curr Top Microbiol Immunol. 2005:295293-324.

61. Rasoloson D, Shi L, Chong CR, Kafsack BF, Sullivan DJ. Copper pathways in Plasmodium falciparum infected erythrocytes indicate an efflux role for the copper P-ATPase. Biochem J. 2004; 381(Pt 3):803-11. [PubMed: 15125686]

62. Bleackley MR, Macgillivray RT. Transition metal homeostasis: from yeast to human disease. Biometals. 2011; 24(5):785-809. [PubMed: 21479832]

63. Myint HY, Berman J, Walker L, et al. Review: Improving the therapeutic index of 8aminoquinolines by the use of drug combinations: review of the literature and proposal for future investigations. Am J Trop Med Hyg. 2011; 85(6):1010-4. [PubMed: 22144436]

64. Ganesan S, Tekwani BL, Sahu R, Tripathi LM, Walker LA. Cytochrome P(450)-dependent toxic effects of primaquine on human erythrocytes. Toxicol Appl Pharmacol. 2009; 241(1):14-22. [PubMed: 19616568]

65. Ganesan S, Chaurasiya ND, Sahu R, Walker LA, Tekwani BL. Understanding the mechanisms for metabolism-linked hemolytic toxicity of primaquine against glucose 6-phosphate dehydrogenase deficient human erythrocytes: evaluation of eryptotic pathway. Toxicology. 2012; 294(1):54-60. [PubMed: 22330256]

66. Abbasi R, Efferth T, Kuhmann C, et al. The endoperoxide ascaridol shows strong differential cytotoxicity in nucleotide excision repair-deficient cells. Toxicol Appl Pharmacol. 2012; 259(3): 302-10. [PubMed: 22280988]

67. Johnson MA, Croteau R. Biosynthesis of ascaridole: iodide peroxidase-catalyzed synthesis of a monoterpene endoperoxide in soluble extracts of Chenopodium ambrosioides fruit. Arch Biochem Biophys. 1984; 235(1):254-66. [PubMed: 6497393]

68. O'Neill PM, Miller A, Bishop LP, et al. Synthesis, antimalarial activity, biomimetic iron(II) chemistry, and in vivo metabolism of novel, potent C-10-phenoxy derivatives of dihydroartemisinin. J Med Chem. 2001; 44(1):58-68. [PubMed: 11141088]

69. O’Neill PM, Posner GH. A medicinal chemistry perspective on artemisinin and related endoperoxides. J Med Chem. 2004; 47(12):2945-64. [PubMed: 15163175]

70. ter Kuile F, White NJ, Holloway P, Pasvol G, Krishna S. Plasmodium falciparum: in vitro studies of the pharmacodynamic properties of drugs used for the treatment of severe malaria. Exp Parasitol. 1993; 76(1):85-95. [PubMed: 8467901]

71. Ponmee N, Chuchue T, Wilairat P, Yuthavong Y, Kamchonwongpaisan S. Artemisinin effectiveness in erythrocytes is reduced by heme and heme-containing proteins. Biochem Pharmacol. 2007; 74(1):153-60. [PubMed: 17498668]

72. Vattanaviboon P, Siritanaratkul N, Ketpirune J, Wilairat P, Yuthavong Y. Membrane heme as a host factor in reducing effectiveness of dihydroartemisinin. Biochem Pharmacol. 2002; 64(1):918. [PubMed: 12106609]

73. Haynes RK, Monti D, Taramelli D, et al. Artemisinin antimalarials do not inhibit hemozoin formation. Antimicrob Agents Chemother. 2003; 47(3):1175. [PubMed: 12604568]

74. Tripathi AK, Gupta A, Garg SK, Tekwani BL. In vitro beta-hematin formation assays with plasma of mice infected with Plasmodium yoelii and other parasite preparations: comparative inhibition with quinoline and endoperoxide antimalarials. Life Sci. 2001; 69(23):2725-33. [PubMed: 11720077]

75. Pandey AV, Tekwani BL, Singh RL, Chauhan VS. Artemisinin, an endoperoxide antimalarial, disrupts the hemoglobin catabolism and heme detoxification systems in malarial parasite. J Biol Chem. 1999; 274(27):19383-8. [PubMed: 10383451]

76. Cheeseman IH, Miller BA, Nair S, et al. A major genome region underlying artemisinin resistance in malaria. Science. 2012; 336(6077):79-82. [PubMed: 22491853]

77. Mayxay M, Khanthavong M, Chanthongthip O, et al. No evidence for spread of Plasmodium falciparum artemisinin resistance to Savannakhet Province, Southern Laos. Am J Trop Med Hyg. 2012; 86(3):403-8. [PubMed: 22403308] 
78. Slater AF, Cerami A. Inhibition by chloroquine of a novel haem polymerase enzyme activity in malaria trophozoites. Nature. 1992; 355(6356):167-9. [PubMed: 1729651]

79. Gilles, H.; Warrell, D. Bruce-Chwatt's Essential malariology. London: Arnold; 1993.

80. Upadhayaya RS, Vandavasi JK, Kardile RA, et al. Novel quinoline and naphthalene derivatives as potent antimycobacterial agents. Eur J Med Chem. 2010; 45(5):1854-67. [PubMed: 20137835]

81. Moenster RP, Jett RA. Mirtazapine and mefloquine therapy for progressive multifocal leukoencephalopathy in a patient infected with human immunodeficiency virus. Am J Health Syst Pharm. 2012; 69(6):496-8. [PubMed: 22382480]

82. Gofton TE, Al-Khotani A, O'Farrell B, Ang LC, McLachlan RS. Mefloquine in the treatment of progressive multifocal leukoencephalopathy. J Neurol Neurosurg Psychiatry. 2011; 82(4):452-5. [PubMed: 20562463]

83. Brickelmaier M, Lugovskoy A, Kartikeyan R, et al. Identification and characterization of mefloquine efficacy against JC virus in vitro. Antimicrob Agents Chemother. 2009; 53(5):1840-9. [PubMed: 19258267]

84. Worthen DB. The national quinine pool: when quinine went to war. Pharm Hist. 1996; 38(3):1437. [PubMed: 11618891]

85. El-Tawil S, Al Musa T, Valli H, et al. Quinine for muscle cramps. Cochrane Database Syst Rev. 2010; (12):CD005044. [PubMed: 21154358]

86. Man-Son-Hing M, Wells G. Meta-analysis of efficacy of quinine for treatment of nocturnal leg cramps in elderly people. BMJ. 1995; 310(6971):13-7. [PubMed: 7827545]

87. Baliga RS, Wingo CS. Quinine induced HUS-TTP: an unusual presentation. Am J Med Sci. 2003; 326(6):378-80. [PubMed: 14671503]

88. Park YA, Hay SN, King KE, et al. Is it quinine TTP/HUS or quinine TMA? ADAMTS13 levels and implications for therapy. J Clin Apher. 2009; 24(3):115-9. [PubMed: 19260037]

89. Slater AF. Chloroquine: mechanism of drug action and resistance in Plasmodium falciparum. Pharmacol Ther. 1993; 57(2-3):203-35. [PubMed: 8361993]

90. O’Neill PM, Bray PG, Hawley SR, Ward SA, Park BK. 4-Aminoquinolines--past, present, and future: a chemical perspective. Pharmacol Ther. 1998; 77(1):29-58. [PubMed: 9500158]

91. O’Neill PM, Ward SA, Berry NG, et al. A medicinal chemistry perspective on 4-aminoquinoline antimalarial drugs. Curr Top Med Chem. 2006; 6(5):479-507. [PubMed: 16719804]

92. Pisciotta JM, Coppens I, Tripathi AK, et al. The role of neutral lipid nanospheres in Plasmodium falciparum haem crystallization. Biochem J. 2007; 402(1):197-204. [PubMed: 17044814]

93. Sullivan DJ. Theories on malarial pigment formation and quinoline action. Int J Parasitol. 2002; 32(13):1645-53. [PubMed: 12435449]

94. Solomonov I, Osipova M, Feldman Y, et al. Crystal nucleation, growth, and morphology of the synthetic malaria pigment beta-hematin and the effect thereon by quinoline additives: the malaria pigment as a target of various antimalarial drugs. J Am Chem Soc. 2007; 129(9):2615-27. [PubMed: 17290993]

95. Cabantchik ZI, Moody-Haupt S, Gordeuk VR. Iron chelators as anti-infectives; malaria as a paradigm. FEMS Immunol Med Microbiol. 1999; 26(3-4):289-98. [PubMed: 10575141]

96. Harvey PW, Bell RG, Nesheim MC. Iron deficiency protects inbred mice against infection with Plasmodium chabaudi. Infect Immun. 1985; 50(3):932-4. [PubMed: 4066038]

97. Raventos-Suarez C, Pollack S, Nagel RL. Plasmodium falciparum: inhibition of in vitro growth by desferrioxamine. Am J Trop Med Hyg. 1982; 31(5):919-22. [PubMed: 6751113]

98. Atkinson CT, Bayne MT, Gordeuk VR, Brittenham GM, Aikawa M. Stage-specific ultrastructural effects of desferrioxamine on Plasmodium falciparum in vitro. Am J Trop Med Hyg. 1991; 45(5): 593-601. [PubMed: 1951869]

99. Loyevsky M, Sacci JB Jr, Boehme P, et al. Plasmodium falciparum and Plasmodium yoelii: effect of the iron chelation prodrug dexrazoxane on in vitro cultures. Exp Parasitol. 1999; 91(2):105-14. [PubMed: 9990337]

100. Mabeza GF, Loyevsky M, Gordeuk VR, Weiss G. Iron chelation therapy for malaria: a review. Pharmacol Ther. 1999; 81(1):53-75. [PubMed: 10051178] 
101. Krungkrai J, Burat D, Kudan S, Krungkrai S, Prapunwattana P. Mitochondrial oxygen consumption in asexual and sexual blood stages of the human malarial parasite, Plasmodium falciparum. Southeast Asian J Trop Med Public Health. 1999; 30(4):636-42. [PubMed: 10928353]

102. Krungkrai J, Prapunwattana P, Krungkrai SR. Ultrastructure and function of mitochondria in gametocytic stage of Plasmodium falciparum. Parasite. 2000; 7(1):19-26. [PubMed: 10743643]

103. Vaidya AB, Mather MW. Mitochondrial evolution and functions in malaria parasites. Annu Rev Microbiol. 2009:63249-67.

104. Learngaramkul P, Petmitr S, Krungkrai SR, Prapunwattana P, Krungkrai J. Molecular characterization of mitochondria in asexual and sexual blood stages of Plasmodium falciparum. Mol Cell Biol Res Commun. 1999; 2(1):15-20. [PubMed: 10527885]

105. Young JA, Fivelman QL, Blair PL, et al. The Plasmodium falciparum sexual development transcriptome: a microarray analysis using ontology-based pattern identification. Mol Biochem Parasitol. 2005; 143(1):67-79. [PubMed: 16005087]

106. Thuma PE, Mabeza GF, Biemba G, et al. Effect of iron chelation therapy on mortality in Zambian children with cerebral malaria. Trans R Soc Trop Med Hyg. 1998; 92(2):214-8. [PubMed: 9764337]

107. Neufeld EJ. Oral chelators deferasirox and deferiprone for transfusional iron overload in thalassemia major: new data, new questions. Blood. 2006; 107(9):3436-41. [PubMed: 16627763]

108. Ding WQ, Lind SE. Metal ionophores - an emerging class of anticancer drugs. IUBMB Life. 2009; 61(11):1013-8. [PubMed: 19859983]

109. Baer K, Klotz C, Kappe SH, Schnieder T, Frevert U. Release of hepatic Plasmodium yoelii merozoites into the pulmonary microvasculature. PLoS Pathog. 2007; 3(11):e171. [PubMed: 17997605]

110. Chilengi R, Juma R, Abdallah AM, et al. A phase I trial to evaluate the safety and pharmacokinetics of low-dose methotrexate as an anti-malarial drug in Kenyan adult healthy volunteers. Malar J. 2011:1063.

111. Reynolds JM, El Bissati K, Brandenburg J, Gunzl A, Mamoun CB. Antimalarial activity of the anticancer and proteasome inhibitor bortezomib and its analog ZL3B. BMC Clin Pharmacol. 2007:713.

112. Bell A. Antimalarial peptides: the long and the short of it. Curr Pharm Des. 2011; 17(25):271931. [PubMed: 21728986]

113. Yount NY, Yeaman MR. Emerging themes and therapeutic prospects for anti-infective peptides. Annu Rev Pharmacol Toxicol. 2012:52337-60.

114. Wells TN, Poll EM. When is enough enough? The need for a robust pipeline of high-quality antimalarials. Discov Med. 2010; 9(48):389-98. [PubMed: 20515606] 


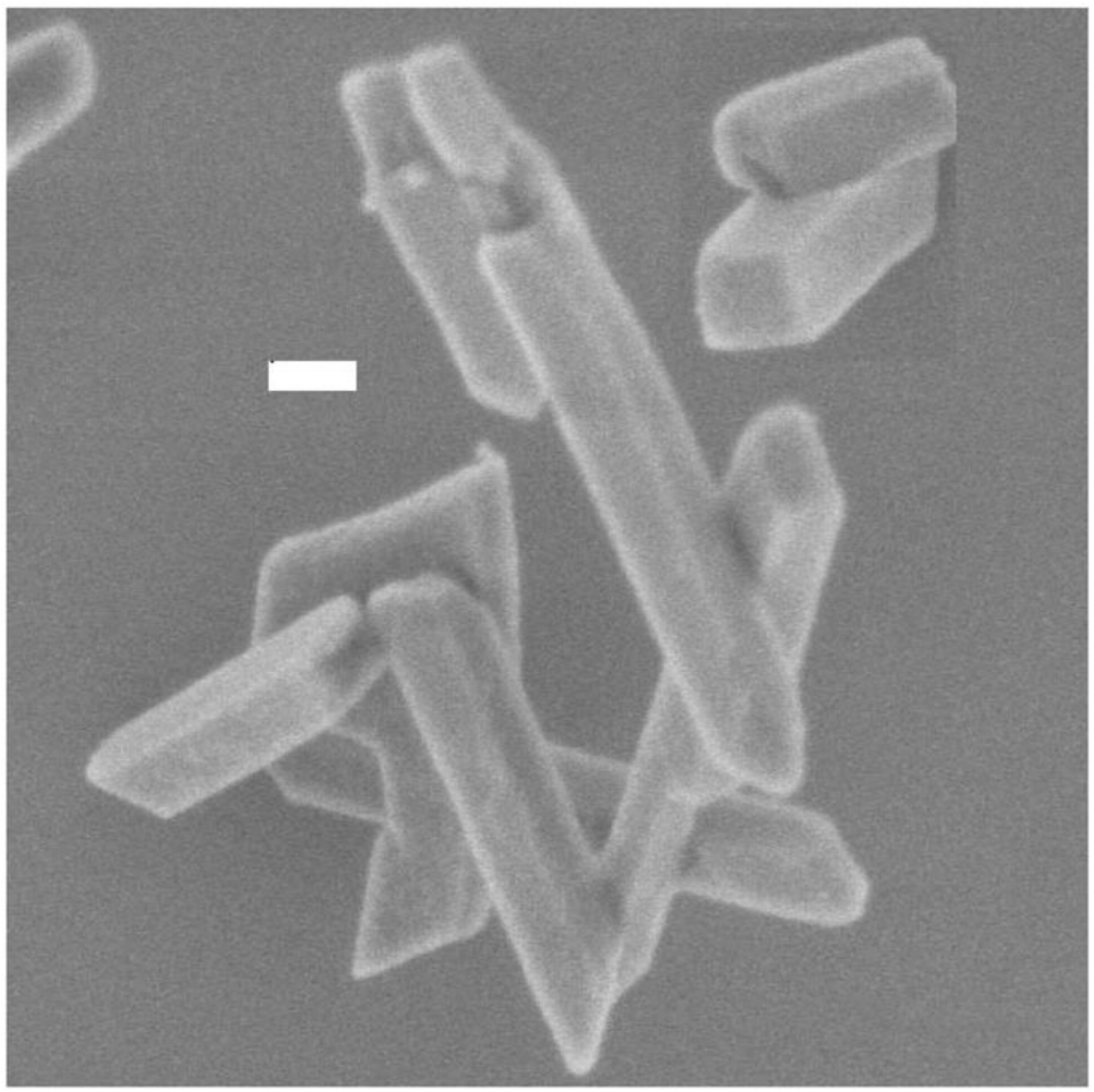

Fig. (1).

Scanning electron microscopy of purified heme crystals from Plasmodium falciparum showing brick like shape. The scale bar is $100 \mathrm{~nm}$. 


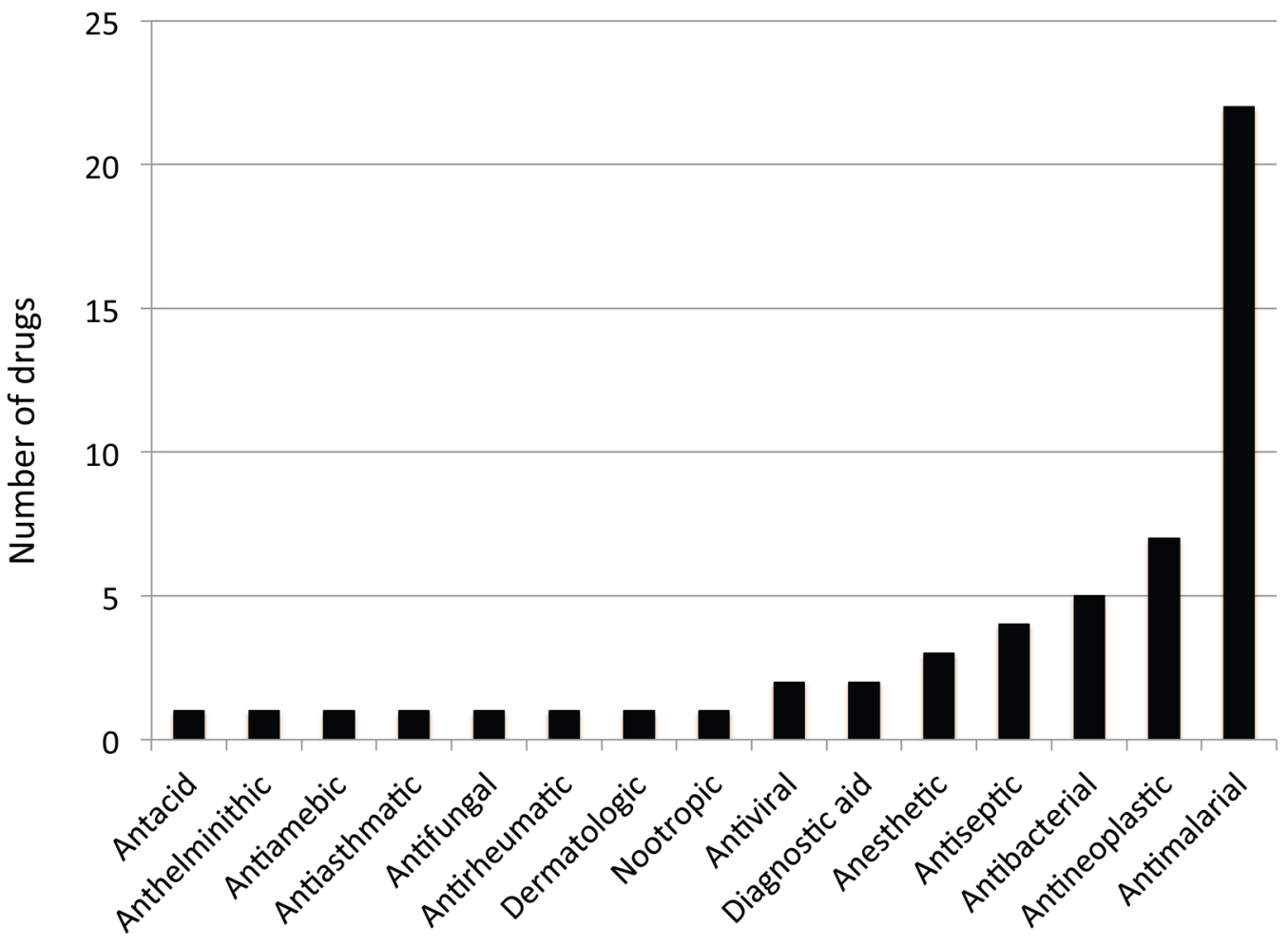

Fig. (2).

The quinoline nucleus is represented in many FDA approved drug indication categories besides antimalarials. A structure search was performed amongst 2815 FDA approved drugs to identify drugs containing a quinoline substructure. The quinoline substructure has many promiscuous uses. 
Table 1

Stage Activity of Nonmutable Plasmodium Drug Targets

\begin{tabular}{|l|c|c|c|c|}
\hline Drug & Liver & Blood & Early gametocyte & Late gametocyte \\
\hline Metal chelators & Yes & Yes & Yes & No \\
\hline 8-aminoquinoline & Yes & No (tafenoquine=yes) & Yes & Yes \\
\hline Other quinolines & No & Yes & Yes & No \\
\hline DNA targets & Yes & Yes & No & No ? \\
\hline Artemisinins & No & Yes & Yes & Yes/No \\
\hline
\end{tabular}


Table 2

Transition Metal Concentrations, Pathways and Representative Enzymes [62]

\begin{tabular}{|c|c|c|c|}
\hline Metal Ion & Concentration in Erythrocyte & Biochemical Pathways & Enzyme Examples \\
\hline Iron $\mathrm{Fe}^{2}-\mathrm{Fe}^{3}$ & $20 \mathrm{mM}(5-10 \mu \mathrm{M}$ nonheme $)$ & $\begin{array}{ll}\mathbf{1} & \text { Heme prosthetic group } \\
\mathbf{2} & \text { Iron sulfur clusters } \\
\mathbf{3} & \text { Nonheme iron proteins }\end{array}$ & $\begin{array}{l}50+\text { iron proteins } 1 \% \text { eukaryote } \\
\text { proteome }) \\
\text { Heme-Hemoglobin, myoglobin and } \\
\text { cytochromes } \\
\text { Fe/S-ferredoxins, hydrogenases and } \\
\text { nitrogenases } \\
\text { Fe-ribonucleotide reductase, iron } \\
\text { oxidases and oxygenases }\end{array}$ \\
\hline Copper $\mathrm{Cu}^{1}-\mathrm{Cu}^{2}$ & $18 \mu \mathrm{M}$ & $\begin{array}{ll}\mathbf{1} & \text { Electron transfer reactions } \\
\mathbf{2} & \text { Multicopper oxidases } \\
\mathbf{3} & \text { Iron metabolism and transport }\end{array}$ & $\begin{array}{l}\text { 30+ copper proteins ( } 1 \% \text { eukaryote } \\
\text { proteome) } \\
\text { Copper-zinc super oxide dismutase } \\
\text { Cupredoxins } \\
\text { Cytochrome c oxidase } \\
\text { Ceruloplasmin ( } 95 \% \text { of plasma copper) } \\
\text { Prion protein (transports copper into } \\
\text { neurons) }\end{array}$ \\
\hline Zinc $\mathrm{Zn}^{2}$ & $153 \mu \mathrm{M}$ & $\begin{array}{ll}\mathbf{1} & \begin{array}{l}\text { DNA-protein interactions-zinc } \\
\text { finger motifs }\end{array} \\
\mathbf{2} & \text { Immunologic } \\
\mathbf{3} & \text { Neuromodulatory } \\
\mathbf{4} & \text { Transcription factors } \\
\mathbf{5} & \text { Matrix metalloproteases } \\
\mathbf{6} & \text { Carboxypeptidases } \\
\mathbf{7} & \begin{array}{l}\text { Metallothionine (absent in } \\
\text { Plasmodium) }\end{array}\end{array}$ & $\begin{array}{l}\text { 300+ zinc proteins ( } 10 \% \text { eukaryote } \\
\text { proteome) } \\
\text { Copper-zinc super oxide dismutase } \\
\text { Carbonic anhydrase } \\
\text { Zinc protoporphyrin IX } \\
\text { Maleate dehydrogenase } \\
\text { Zinc aminopeptidase } \\
\text { Alkaline phosphatases } \\
\text { Insulin } \\
\text { Phospholipase C }\end{array}$ \\
\hline
\end{tabular}

